\title{
A randomized clinical trial comparing intravaginal glyceryl trinitrate (nitric oxide donor) plus artificial sweeping of membrane versus artificial sweeping of membrane alone for cervical ripening at term pregnancies with unfavourable cervix
}

\author{
G R R N Jayantha ${ }^{a}$, S Nanayakkara ${ }^{b}$
}

\begin{abstract}
Introduction: There are several reasons to have post-dated pregnancies in uncomplicated pregnancies in labour wards. The policy of cervical ripening at term will reduce the risk and their complications associated with postdate pregnancies. Artificial sweeping of membranes and nitric oxide donors are useful cervical ripening methods used across the world. This study was carried out to compare the efficacy of cervical ripening by administration of intravaginal glyceryl trinitrate plus artificial sweeping of membranes versus artificial sweeping of membranes alone.

Objectives: To compare of the efficacy, the spontaneous onset of labour rate, the labour outcome, the duration from induction to the delivery time of baby and adverse maternal and fetal outcomes of cervical ripening by administrating of intravaginal glyceryl trinitrate combined with artificial sweeping of membranes versus artificial sweeping of membranes alone.

Methodology: This was a double blinded randomized clinical trial carried out in a major obstetric unit in Sri Lanka. Having excluded the subjects according to the exclusion criteria, rest of the sample was divided into cases and controls. Sample randomization done by using stratified block randomization technique with sealed envelope. Artificial sweeping of membranes done together with intravaginal Glyceryl trinitrate was inserted for the cases and artificial sweeping of membranes alone was performed for the control group. Number of Spontaneous onsets of labour, improvement of the modified Bishop's Score, delivery time and labor outcome were assessed. Data were analyzed by using SPSS software.

Results: Mean age, parity and gestational age were matched in both intervention and control group. Number of mothers with spontaneous onset of labour within 24 hours were significantly increased $(p<0.001)$ in both primi and multiparous women in therapeutic arm compare to controls. The modified Bishop's score was improved in both primi and multi women, in addition, multiparous mothers in therapeutic arm showed the statistically significant improvement $(p<0.001)$ of the modified Bishop's score compare to control arm. There was reduction in the time duration from induction to delivery of baby in both multi and primi therapeutic arms, and reduction is statistically significant in multiparous $(p=0.01)$ women, but reduction is not significant in primi mothers. There were no significant differences in mode of delivery, maternal and fetal adverse out comes in between intervention and control arms other than the headache $(P<0.001)$, of which significantly reported in therapeutic arm.

Conclusion and recommendation: Intravaginal glyceryl trinitrate combined with artificial sweeping of membranes is associated with increased rate of spontaneous onset of labour at term, improvement of modified Bishop's score and reduction of time duration from induction to delivery in term pregnancies. It had minimal maternal and fetal adverse outcome. Further studies should be carried out to find optimal dose and frequency, long term safety, specific side effect and possibility of using in outpatient department relation to to the glyceryl trinitrate intravaginal route.
\end{abstract}

Key words: cervical ripening, artificial sweeping of membranes, intravaginal glyceryl trinitrate, spontaneous onset of labour

Sri Lanka Journal of Obstetrics and Gynaecology 2021; 43: 154-165

DOI: http://doi.org/10.4038/sljog.v43i3.8005

${ }^{\text {a }}$ Postgraduate Institute of Medicine, Colombo, Sri Lanka

${ }^{\mathrm{b}}$ Castle Street Hospital for Women, Colombo, Sri Lanka

Correspondence: GRRNJ, e-mail: nalakajayantha85@gmail.com

ID https://orcid.org/0000-0002-5698-2483

Received $7^{\text {th }}$ August 2021

Accepted $3^{\text {rd }}$ November 2021

This is an open-access article distributed under the terms of the Creative Commons Attribution 4.0 International License, which permits unrestricted use, distribution and reproduction in any medium provided the original author and source are credited. 


\section{Introduction}

Postdated pregnancies means that the pregnancies are delivered beyond the term. According to the various geographic population and individual practice pattern, prevalence of postdates pregnancies is up to $18 \%$ in some countries. There are well known factors that associated with post dates are nulliparity, high body mass index (BMI) and elderly motherhood ${ }^{1,2}$. post-term pregnancies are at higher risk of getting still birth, intrauterine death, meconium aspiration syndrome, low amniotic fluid index ${ }^{3}$, macrosomia, fetal distress ${ }^{4}$ in labour. It also increases maternal morbidity such as anxiety, infection, and increased rate of caesarean delivery, obstructed labour and perineal damage ${ }^{4}$.

The policy of cervical ripening (CR) at term will reduce the risk of postdated pregnancies as well as their associated complications ${ }^{3,4}$. The successful labour pre requires cervical ripening. Depending on the method of CR, the success rate of induction of labour (IOL) may vary. Cervical ripening methods can be classified into mechanical or pharmacological such as Foley catheters, sweeping of membranes, cervical massage, and the agents such as prostaglandins ${ }^{5}$, nitric oxide donors $^{6,7}$.

The cervix consists of mainly elastin (85\%), collagen, laminin, hyalarunic acid, fibronectin and $15 \%$ consists of smooth muscles and epithelium. At latter part of pregnancy, these collagens will be broken down by proteolytic enzymes such as matrix-metalo-proteinase (MMP). That will lead to cervical softening, dilatation and effacement. This process is one of the physiological inflammatory events occurred in human body ${ }^{5}$, for which several markers are involved like cytokines, interleukin, PGE and NO.

Glyceryl trinitrate (GTN) is known as a nitric oxide donor, can be used to dilate the cervix without contracting the myometrium of the uterus. The GTN is safe $^{7,8}$, less expensive, easy to apply, freely available and causes less maternal and fetal complications ${ }^{7}$. However oral GTN is associated with minor side effects like maternal headache, palpitations and postural hypotension ${ }^{8}$. But intravaginal glyceryl trinitrate has minimum systemic side effects ${ }^{9}$.

Artificial sweeping of membranes (ASM) is a mechanical method ${ }^{5,10}$ uses to ripen the cervix which is carried out by vaginal examination followed by separation of the fetal membranes from the cervix and lower uterine segment ${ }^{5}$. The sweeping of membrane will augment the synthesis and secretion of endogenous prostaglandin (PGE) from lower uterine segment. The ASM has a better outcome when it is performed at 40 weeks of period of gestation (POG ${ }^{55,11}$. Sweeping membranes is rarely associated with pre-rupture of membrane, and more maternal discomfort comparing to pharmacological agents ${ }^{12}$. But there is no proven significant risk of maternal and fetal infection ${ }^{9,13}$.

The methods for cervical ripening for unfavorable cervix are differ from unit to unit ${ }^{12}$. Modified Bishop's Score (MBS) 14 is used to assess the favorability of cervix. Induction of labour is pre planned initiation of labour prior to onset of SOL to prevent complications to the fetus or mother. According to the World reproductive library (RHL) ${ }^{15}$, globaly $10 \%$ of all deliveries involve IOL and, in Sri Lanka it is approximately 35.5\%. The most common reason for induction of labour is postdates or post maturity ${ }^{5}$. Other indications for induction are pre-rupture of membranes (PROM), fetal growth restriction, maternal medical disorders, chorioamnionitis and some social reasons.

Glycerl trinitrate, chemically known as nitroglycerin $\left(\mathrm{C}_{3} \mathrm{H}_{5} \mathrm{~N}_{3} \mathrm{O}_{9}\right)$, has the molar weight of $227.087 \mathrm{~g} / \mathrm{mol}$. GTN is well absorbed through mucus membranes including vaginal mucosa and $11-60 \%$ are bound to protein in plasma ${ }^{16}$. Its action begins within 1-2 minutes and enter to the smooth muscle and activating cGMP. They are used for cervical ripening due to its capability in relaxation of both myometrium and vascular smooth muscles. Nitric oxide donors also cause the stimulation of PGE production by activating cyclo-oxygenase pathway (COX) and inhibition of thromboxane $\mathrm{A}_{2}$. Additionally, NO increases the uterine blood flow that eventually enhance the process of cervical ripening.

GTN is a 'category C' drug where human studies are not available or human studies are not done previously. There, trials are limited in child bearing women's or do not have evidence that GTN having direct or indirect fetal effects. Adverse reactions identified in GTN are headache $(64 \%)$, and very rarely shows prolonged headache (0.1-0.01\%). Studies have shown that rarely, GTN cause hypotension, bradycardia and circulatory collapse, vomiting and dry mouth. Experience of erythema, pruritus, burning sensation, irritation, eczema and cerebral ischemia are extremely rare ${ }^{23}$. 


\section{Study plan}

Total $n=260$; Obtained written consent at 40 weeks of POG by main investigator after assessing the subjects carefully by inclusion and exclusion criteria and then prepared for cervical ripening. Singleton pregnancies with unfavorable CX (<6 MBS) taken in to the study.

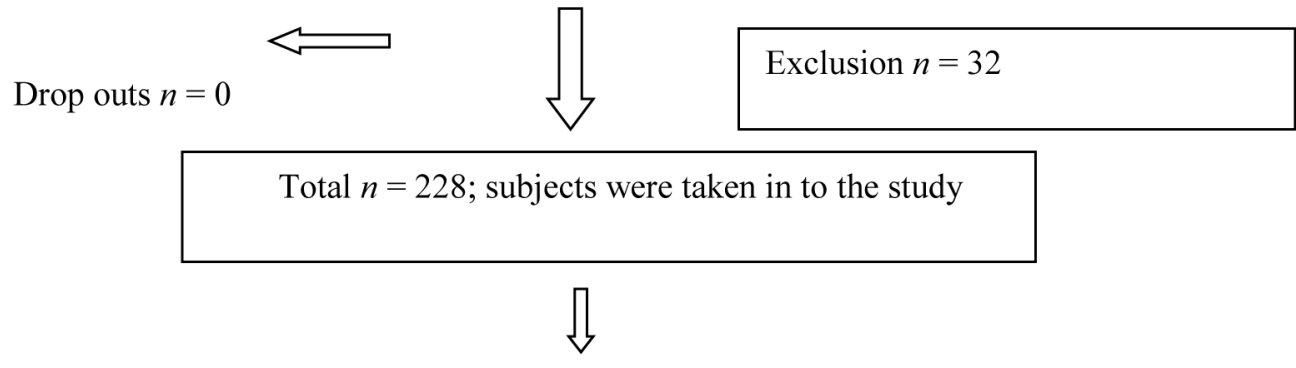

Cases $n=112$
Primi/ Multi

Artificial sweeping of membranes and insertion of one dose of $500 \mu \mathrm{g}$ of GTN intra vaginally at $7 \mathrm{am}$ by a colleague at 40 weeks POG

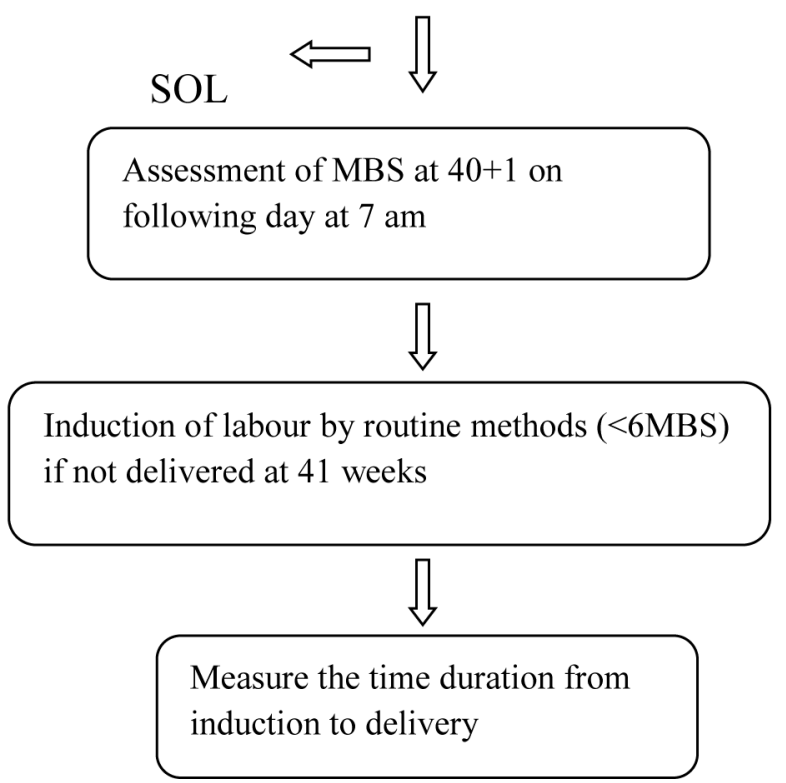

Artificial sweeping of membrane and insertion of placebo (folic acid) at 7 am by a colleague at 40 weeks POG

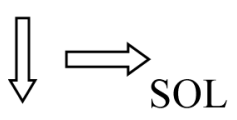

Assessment of MBS at $40+1$ on following day at 7 am

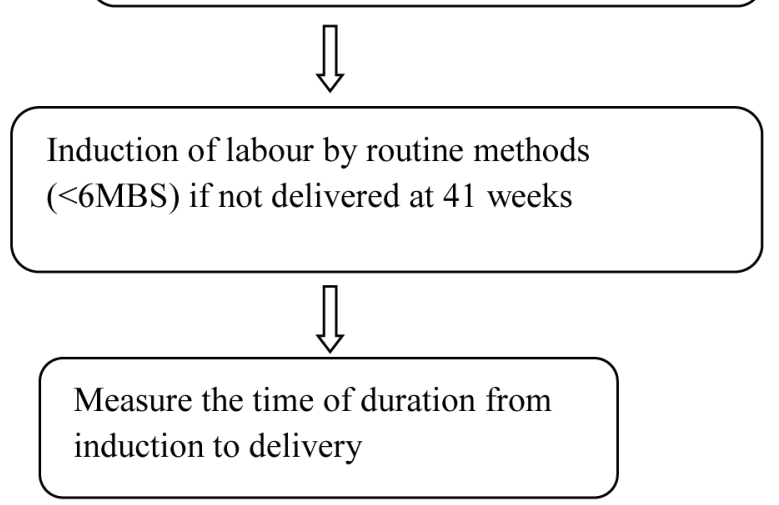

Figure 2. Flow chart for study procedure from patient recruitment, randomization and assessment of the outcomes. 


\section{Research methodology}

According to the Cochrane review which was carried out in United Kingdom regarding pharmacological cervical ripening agents, NO donors were compared with other routinely used drugs such as PGE for ripening the cervix. They found to have no significant difference between effectiveness of NO donors and those routine agents. In addition, NO donors can be used in outpatient setting ${ }^{17}$ rather than PGE which used in for inpatient settings.

In 2012 a clinical trial has been carried out at Thailand, using GTN versus PGE2 as cervical ripening agents ${ }^{8}$. At this study, they found that GTN is having lower major side effects (tachysystole) and having higher minor side effects (headache) ${ }^{8}$ compared to PGE2. But PGE had better outcome compared to the NO donors $^{6,8}$. The major side effects like hyperstimulation are commoner with PGE induction ${ }^{18,19}$.

Isosorbid mononitrate (ISMN) is another NO donor agent that used as a CR agent ${ }^{9,17}$. There are several researches carried out by using ISMN. A randomized trial recently done in India ${ }^{17}$, shows that ISMN significantly ripen the cervix, it further reduces the need of other additional ripening agents and having lesser major fetal and maternal side effects ${ }^{17,18}$.

General objective in this study is to compare efficacy of cervical ripening by administration of single dose of intravaginal glyceryl trinitrate plus artificial sweeping of membranes, in singleton uncomplicated pregnancies at term. Specific objectives are to measure the number of spontaneous onsets of labour, compare the favorability of cervix for induction of labour, compare the time duration from induction to the delivery of baby and measure the adverse maternal and fetal effects.

Inclusion criteria for this study was set as women completed 40 weeks of gestation, singleton pregnancy along with cephalic presentation, and unfavorable cervix. Pregnancies with previous cesarean section, intra uterine growth restriction, gestational diabetes, pregnancy induced hypertension and pre-rupture of membranes were excluded. Randomization and allocation done, PG 1-130 (for primi) and MG 1-130 (for multi), using the stratified randomization technique. For study group ASM was performed once and inserted intravaginal GTN 500mcg at 7 am morning at 40 weeks of POG. For the control group, membranes were swept and inserted placebo (folic acid) at 7 am at 40 weeks of POG. Then vaginal examination was carried out in both groups to assess the MBS if the labour is established. Otherwise, MBS assessed on following day at 7 am (after 24 hours).

Mothers who underwent spontaneous onset of labour within next 24 hours, were offered with amniotomy and mothers who did not undergo spontaneous onset of labour, their Bishop's score were assessed following day morning. Those mothers with unfavorable cervix $(\mathrm{MBS}<6)$, were further managed according to the ward protocols.

Minimal sample size was calculated by using $80 \%$ of power and $95 \%$ of confidence interval. Total sample size was calculated as 260 according to the Formula (according to Kasiulevicus1, Sapoka1 and Filipaviciute et al) $)^{20}$.

\section{Results}

Total number of 228 samples were taken for randomization while 112 cases and 116 were controls

The mean age of the sample was $29.85+/-4.3$ years, which followed near normal Gaussian curve. Graph 1

The frequencies of study population according to the parity, 63\% were primi, 30\% were second pregnancy and $6.6 \%$ were in their third pregnancy which showed right skewed distribution. Graph 2

Each group of the cases and control were equally distributed and there was no statistical difference between, age, parity number and period of gestation in two groups.

\section{a) Spontaneous onset of labour in primi gravid}

The number of mothers who underwent spontaneous onset of labour (SOL) within 24 hours after the cervical ripening were analyzed by using Chi square test. There were 46 mothers undergone SOL while 14 mothers not undergo SOL, in therapeutic arm in primi mothers. In contrast, 55 mothers of control arm did not undergo SOL, while 28 primi mothers underwent SOL. In primi mothers, there were statistically significant $\left(\mathrm{X}^{1}=25.501, \mathrm{p}<0.001\right)$ difference of spontaneous onset of labour in intervention group compared to control groups. Graph 3 


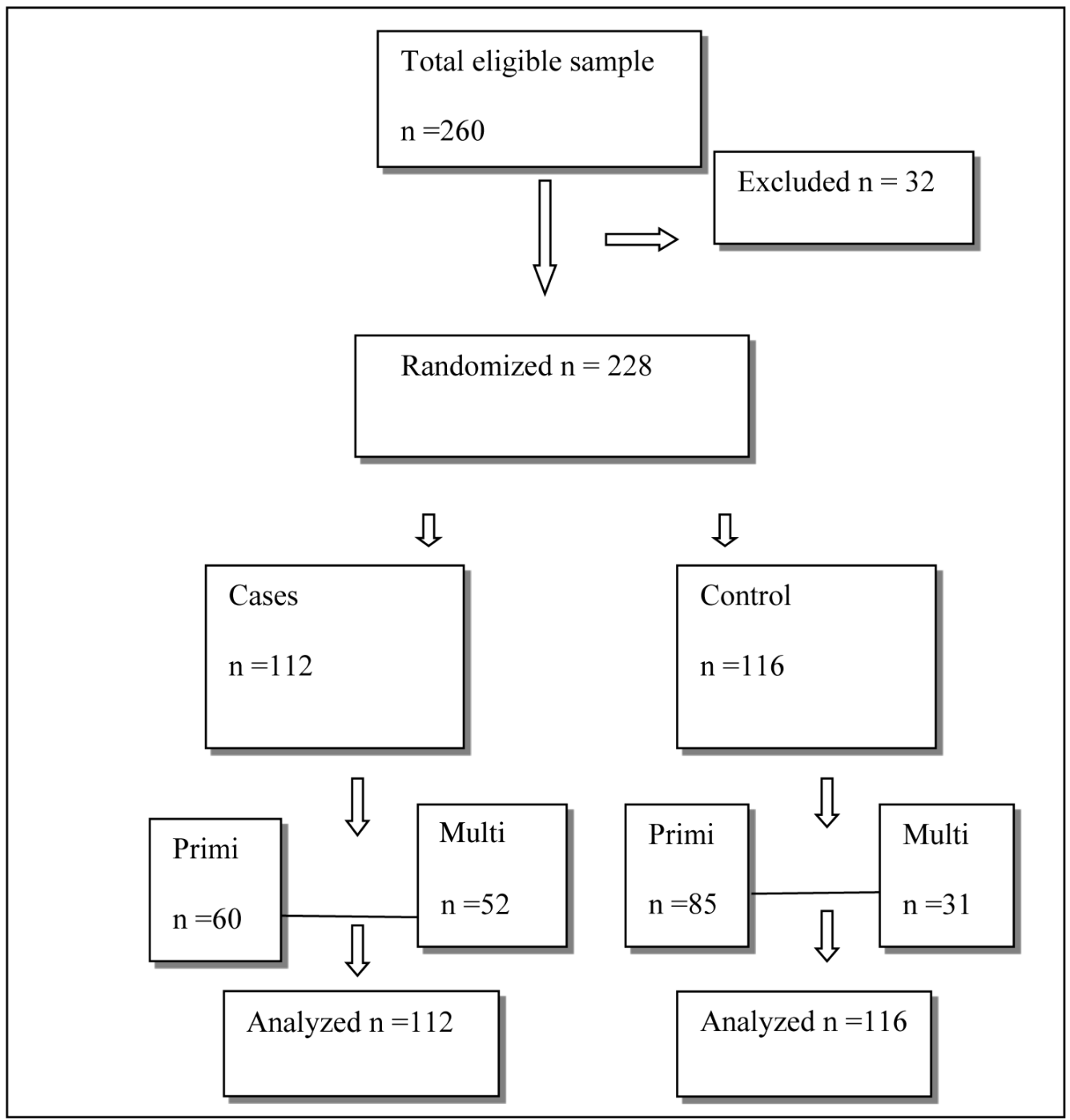

Figure 3. CONSORT flow diagram for recruitment and randomization of sample.

\section{b) Spontaneous onset of labour in multi gravid mothers}

In therapeutic arm of multi-mothers, 27 mothers undergone SOL while 15 mothers not undergone SOL. Whereas, 15 mothers in control arm undergone SOL while, 21 mothers did not. There was a statistically significant $\left(\mathrm{X}^{1}=13.085, \mathrm{p}=0.001\right)$ difference of number of mothers who had spontaneous onset of labour between intervention and control group. Graph 4, Graph 5

\section{c) Modified Bishop's Score improvement in two groups}

Mean Bishop's Score improvement seen in 2.8 and 1.8 in therapeutic and control arms respectively in primi mothers. Therefore, no significant $\left(\mathrm{t}_{68}=0.31, \mathrm{p}=0.58\right)$ improvement of the MBS was observed in therapeutic arm compared to control arm in primi.

At the same time, multigravida mothers had mean MBS improvement 4.8 and 2.8 in therapeutic and control arms respectively. The results showed significant $\left(\mathrm{t}_{39}=5.13, \mathrm{p}=0.03\right)$ improvement of the MBS in multigravida mothers by adding GTN in addition to ASM. Table 3

\section{d) Average delivery time between two groups}

Both groups of intervention and control arm were assessed by time duration from induction to delivery in minutes. In primi mothers, there were no significant 
difference $\left(\mathrm{T}_{100}=3.84, \mathrm{p}=0.92\right)$ in induction to delivery time between two groups. But in multi gravid mothers mean time of delivery were 264 minutes for therapeutic arm and 384 minutes for control arm. These results highlight the significant reduction $\left(\mathrm{t}_{29} \cdot 41=2.53\right.$, $\mathrm{p}=0.01$ ) of time duration from induction to delivery between intervention and control groups in multi mothers. Table 4, Graph 6.

\section{e) Mode of delivery between two groups}

Mode of delivery (MOD) was assessed between intervention group and control group. There was no statistically significant difference $\left(\mathrm{X}^{1}=0.224, \mathrm{P}=0.63\right)$ between two groups according to the MOD (vaginal or caesarean section). Graph 7
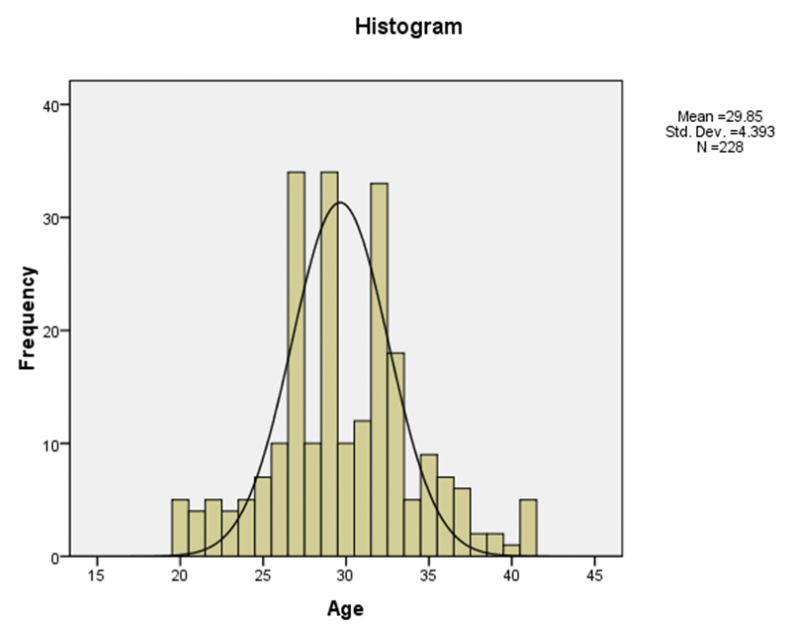

Graph 1. Distribution of the entire sample in normal Gaussian curve

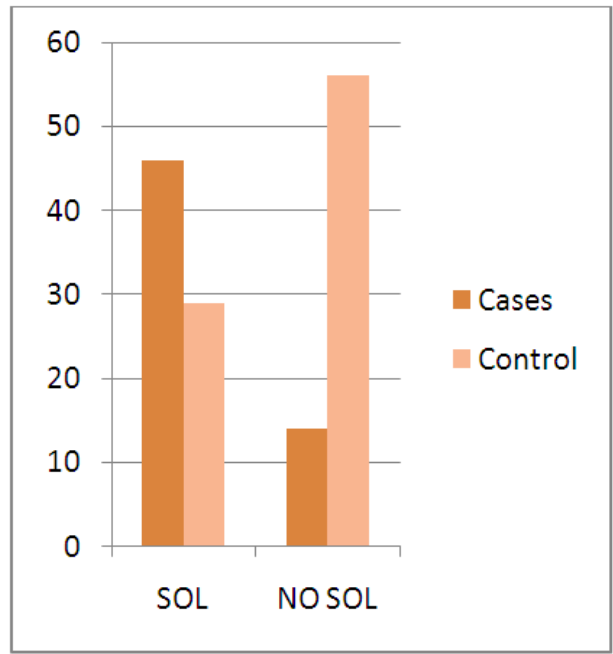

Graph 3. Spontaneous onset of labour between primi mothers.

\section{(f) Fetal and maternal adverse outcomes}

In therapeutic arm, there were $4.5 \%$ reported cases of spontaneous rupture of membranes (SROM). The headache was reported in $36 \%$ of mothers who took GTN which was significantly high compared to placebo $(\mathrm{p}<0.001)$. CTG deceleration reported in $4.5 \%$, meconium-stained liquor in $4.5 \%$ and peri-natal infection occurred in $7.5 \%$ of babies of intervention group.

In further analysis, spontaneous rupture of membranes (SROM) occurred in $4 \%$ and maternal infection reported in $5.2 \%$ of control group. CTG deceleration reported in $5.2 \%$, meconium-stained liquor in $5 \%$ and peri-natal infection occurred in $4.3 \%$ of babies of control group. Table 5, Table 6

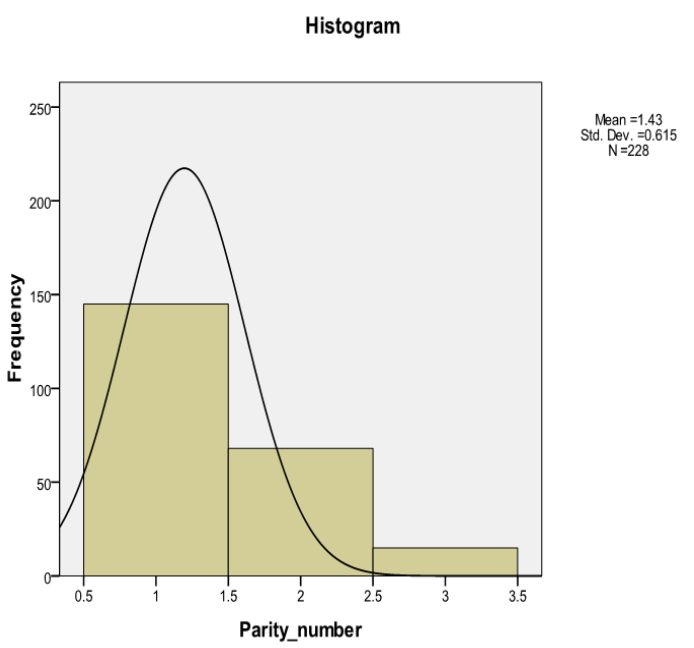

Graph 2. Distibution of parity in study population.

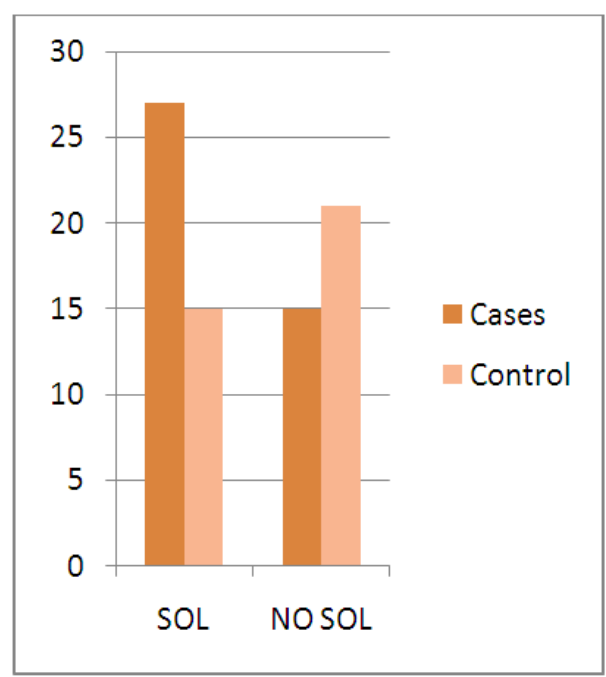

Graph 4. Spontaneous onset of labour between multi mothers. 
Table 1. Modified Bishop's score (MBS)

\begin{tabular}{|l|c|c|c|c|}
\hline Parameter & $\mathbf{0}$ & $\mathbf{1}$ & $\mathbf{2}$ & $\mathbf{3}$ \\
\hline Position of the cervix & Posterior & Middle & Anterior & - \\
Dilatation (cm) & Closed & $1-2$ & $3-4$ & $>5 \mathrm{~cm}$ \\
Effacement & $0-30 \%$ & $40-50 \%$ & $60-70 \%$ & $>80 \%$ \\
Fetal station & -3 & -2 & -1 or 0 & +1 or +2 \\
Consistency & Firm & Medium & Soft & - \\
\hline
\end{tabular}

MBS >6 = favorable cervix, MBS d"6 = unfavorable cervix

Table 2. Basic demographic data between cases and control population

\begin{tabular}{|l|c|c|c|c|}
\hline & \multicolumn{2}{|c|}{ Intervention } & \multicolumn{2}{c|}{ Control } \\
\hline & Primi & Multi & Primi & Multi \\
Age (years) & $27.8(\mathrm{SD}=-3.5)$ & $32.9(\mathrm{SD}=-2.8)$ & $28.2(\mathrm{SD}=-3.4)$ & $33.1(\mathrm{SD}=-5.67)$ \\
POG (weeks) & 40 & 40 & 40 & 40 \\
\hline
\end{tabular}

POG $=$ Period of gestation

Table 3. Modified bishop's score (MBS) difference between cases and control

\begin{tabular}{|c|c|c|}
\hline & Cases (mean) & Control (mean) \\
\hline MBS difference in primi & $2.5(\mathrm{SD}=-2.4)$ & $1.8(\mathrm{SD}=-0.6)$ \\
MBS difference in multi & $4.8(\mathrm{SD}=-1.2)$ & $2.8(\mathrm{SD}=-0.6)$ \\
\hline
\end{tabular}

Table 4. Mean induction to delivery time between cases and control

\begin{tabular}{|l|c|c|}
\hline & Cases & Control \\
\hline $\begin{array}{l}\text { Mean induction to delivery } \\
\text { time in primi (minutes) }\end{array}$ & $366.02(\mathrm{SD}=-197.36)$ & $511.65(\mathrm{SD}=-213.50)$ \\
$\begin{array}{l}\text { Mean induction to delivery } \\
\text { time in multi (minutes) }\end{array}$ & $264.30(\mathrm{SD}=-130.81)$ & $382(\mathrm{SD}=-193.79)$ \\
\hline
\end{tabular}


Table 5. Feto-maternal adverse outcome

\begin{tabular}{|l|c|c|}
\hline Variable & GTN+ASM & ASM \\
\hline Headache & $36 \%$ & $0 \%$ \\
Hyper stimulation & $0 \%$ & $0 \%$ \\
PPH & $1 \%$ & $0 \%$ \\
Maternal infection & $2 \%$ & $5 \%$ \\
Pre-rupture of membranes & $5 \%$ & $4 \%$ \\
Non reassuring on CTG & $4.5 \%$ & $5 \%$ \\
Meconium & $4.5 \%$ & $5 \%$ \\
Still birth & $0 \%$ & $0 \%$ \\
Neonatal infection & $7.5 \%$ & $4 \%$ \\
\hline
\end{tabular}

Table 6. Summary of results

\begin{tabular}{|c|c|c|c|c|}
\hline & \multicolumn{2}{|c|}{ Intervention arm } & \multicolumn{2}{|c|}{ Control arm } \\
\hline & Primi & Multi & Primi & Control \\
\hline Sample size & \multicolumn{2}{|c|}{112} & \multicolumn{2}{|c|}{116} \\
\hline $\begin{array}{l}\text { Age, POG, parity } \\
\text { number }\end{array}$ & \multicolumn{2}{|c|}{$\begin{array}{l}\text { Equally balanced in both } \\
\text { intervention and control groups }\end{array}$} & \multicolumn{2}{|c|}{$\begin{array}{l}\text { Equally balanced both } \\
\text { intervention and control groups }\end{array}$} \\
\hline $\begin{array}{l}\text { Spontaneous onset of } \\
\text { labour within } 24 \text { hours }\end{array}$ & $\begin{array}{l}\text { Significantly } \\
\text { increased }\end{array}$ & $\begin{array}{l}\text { Significantly } \\
\text { increased }\end{array}$ & $\begin{array}{l}\text { No significant } \\
\text { difference }\end{array}$ & $\begin{array}{l}\text { No significant } \\
\text { difference }\end{array}$ \\
\hline $\begin{array}{l}\text { Mean bishops score } \\
\text { difference }\end{array}$ & $\begin{array}{l}\text { Significant } \\
\text { difference }\end{array}$ & $\begin{array}{l}\text { Significantly } \\
\text { increased }\end{array}$ & $\begin{array}{l}\text { No significant } \\
\text { difference }\end{array}$ & $\begin{array}{l}\text { No significant } \\
\text { difference }\end{array}$ \\
\hline Induction to delivery time & $\begin{array}{l}\text { Significant } \\
\text { difference }\end{array}$ & $\begin{array}{l}\text { Significantly } \\
\text { reduced }\end{array}$ & $\begin{array}{l}\text { No significant } \\
\text { difference }\end{array}$ & $\begin{array}{l}\text { No significant } \\
\text { difference }\end{array}$ \\
\hline Primary mode of delivery & \multicolumn{2}{|c|}{ No significant difference } & \multicolumn{2}{|c|}{ No significant difference } \\
\hline Adverse maternal outcome & \multicolumn{2}{|c|}{ Headache significantly increased } & \multicolumn{2}{|c|}{ No significant difference } \\
\hline Adverse fetal outcome & \multicolumn{2}{|c|}{ No significant difference } & \multicolumn{2}{|c|}{ No significant difference } \\
\hline
\end{tabular}




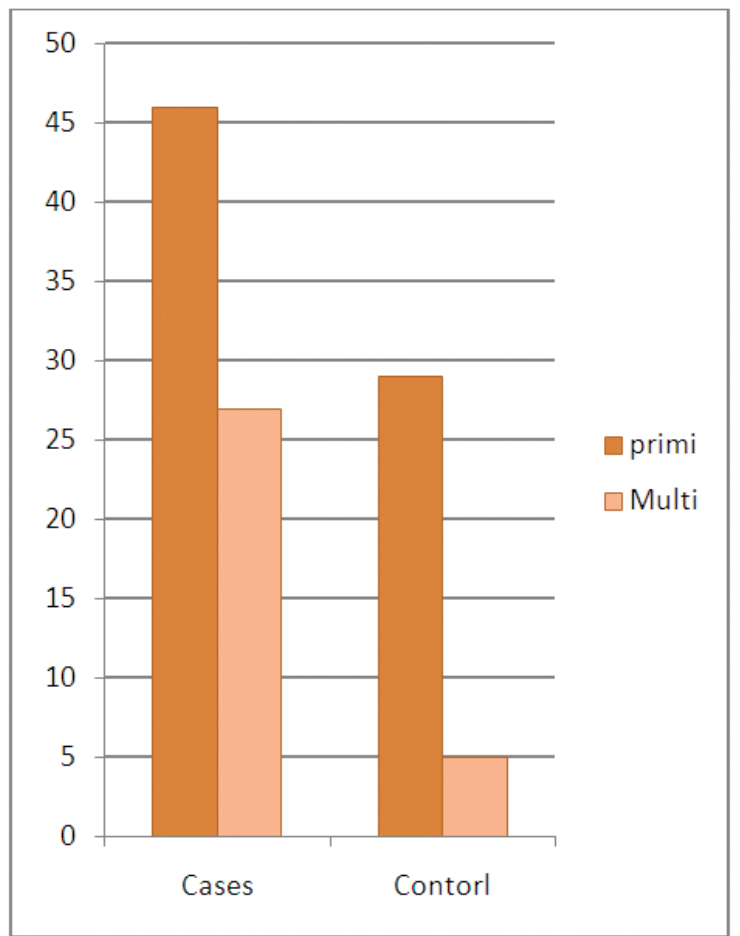

Graph 5. Spontaneous onset of labour rate in intervention and control arms.

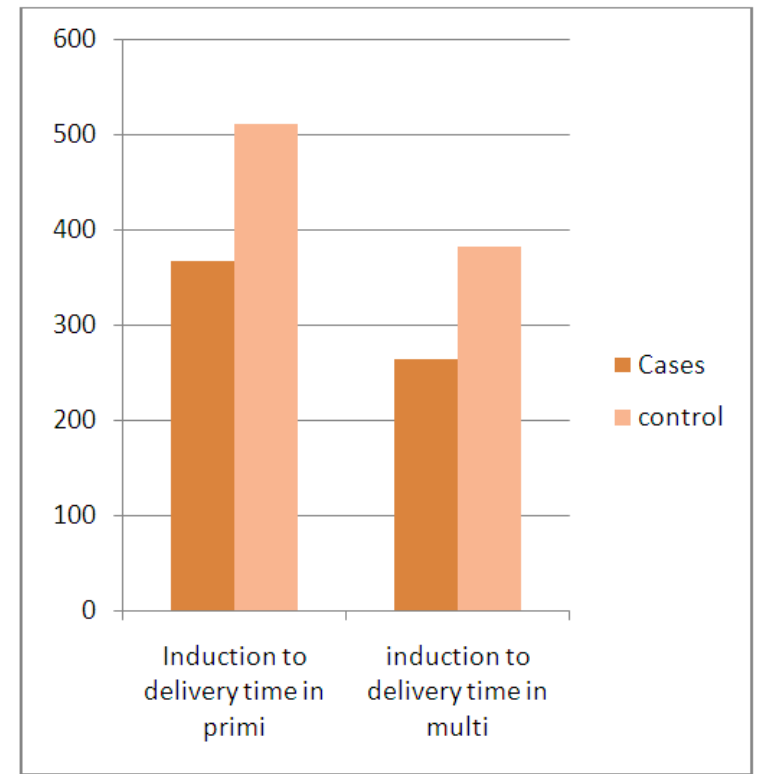

Graph 6. Induction to delivery time in two groups.

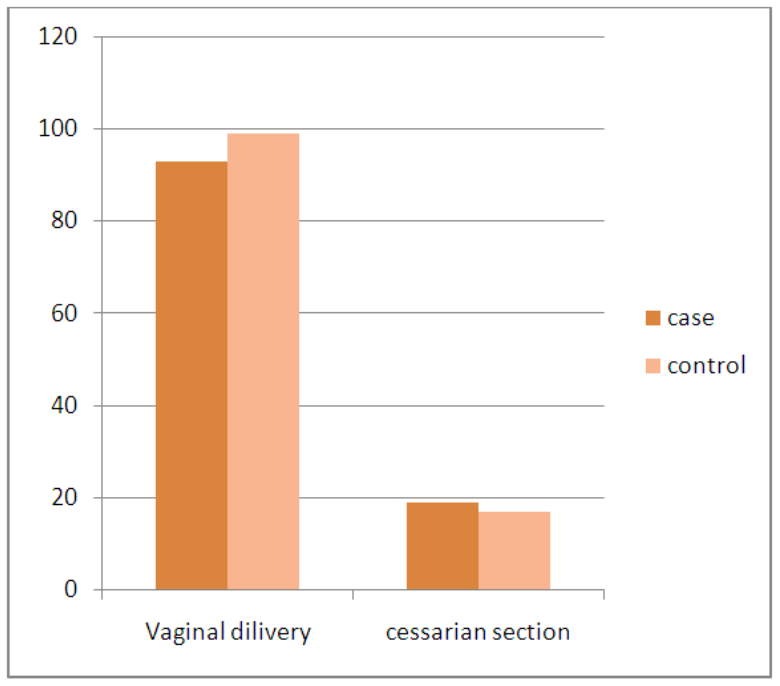

Graph 7. Mode of delivery between two groups. 
Table 7. Results of comparison and difference between previous research (NSD=no statistical difference, GTN-Glycerol trinitrate, ISMN-Isosorbid mononitrate, CTG-Cardiotocograph)

\begin{tabular}{|c|c|c|c|c|c|c|}
\hline Study & $\begin{array}{l}\text { Spontaneous onset } \\
\text { of vaginal delivery } \\
\text { within } 24 \text { hours } \\
(p<0.05)\end{array}$ & $\begin{array}{l}\text { Bishops score } \\
\text { improvement } \\
(p<0.05)\end{array}$ & $\begin{array}{l}\text { Induction to } \\
\text { delivery time } \\
(\mathbf{p}<0.05)\end{array}$ & $\begin{array}{l}\text { Mode of } \\
\text { delivery } \\
(p<0.05)\end{array}$ & $\begin{array}{l}\text { Maternal } \\
\text { adverse } \\
\text { outcome }\end{array}$ & $\begin{array}{l}\text { Fetal } \\
\text { adverse } \\
\text { outcome }\end{array}$ \\
\hline $\begin{array}{l}\text { Current } \\
\text { research }\end{array}$ & $\begin{array}{l}\text { Intervention arm - } \\
\text { significantly } \\
\text { increased in } \\
\text { (multi } p=0.001 \text {, } \\
\text { primi }<0.001 \text { ) }\end{array}$ & $\begin{array}{l}\text { Intervention } \\
\text { arm - significantly } \\
\text { increased in } \\
\text { multi ( } \mathrm{p}=0.03) \text {, } \\
\text { primi - No } \\
\text { statistical } \\
\text { difference } \\
(\mathrm{p}=0.58)\end{array}$ & $\begin{array}{l}\text { Intervention } \\
\text { arm - significantly } \\
\text { increased in } \\
\text { multi ( } \mathrm{p}=0.015) \\
\text { primi - No } \\
\text { statistical } \\
\text { difference } \\
(\mathrm{p}=0.92)\end{array}$ & $\begin{array}{l}\text { No statistical } \\
\text { difference in } \\
\text { intervention } \\
\text { and control }\end{array}$ & $\begin{array}{l}\text { Headache is } \\
\text { high in } \\
\text { intervention } \\
\text { group } \\
(p<0.001)\end{array}$ & $\begin{array}{l}\text { No statistical } \\
\text { difference }\end{array}$ \\
\hline $\begin{array}{l}\text { Filmena P et al; } \\
2005^{7}\end{array}$ & $\begin{array}{l}\text { GTN+Dinoprostone } \\
\text { group- } \\
\text { No Significant } \\
\text { difference }\end{array}$ & $\begin{array}{l}\text { GTN+Dinoprostone } \\
\text { group - significantly } \\
\text { improved }(p=0.001) \\
\text { compared to } \\
\text { dinoprostone alone }\end{array}$ & $\begin{array}{l}\text { GTN+Dinoproston } \\
\text { group - significantly } \\
\text { reduced ( } \mathrm{p}=0.03) \\
\text { compared to } \\
\text { dinoprostone alone }\end{array}$ & $\begin{array}{l}\text { No statistical } \\
\text { difference }\end{array}$ & $\begin{array}{l}\text { Statically } \\
\text { significant } \\
\text { difference in } \\
\text { tachysystole in } \\
\text { therapeutic } \\
\text { arm ( } \mathrm{p}=0.02)\end{array}$ & $\begin{array}{l}\text { No statistical } \\
\text { difference }\end{array}$ \\
\hline $\begin{array}{l}\text { Yuthika Sharma } \\
\text { et al; } 2005^{6}\end{array}$ & Not measured & $\begin{array}{l}\text { All arms including } \\
\text { GTN arm, } \\
\text { dinoprostone arm, } \\
\text { misoprostol arm } \\
\text { - significantly } \\
\text { increased }(\mathrm{p}<0.001 \text { ) }\end{array}$ & $\begin{array}{l}\text { No significant } \\
\text { difference }\end{array}$ & $\begin{array}{l}\text { Cesarean section } \\
\text { and instrumental } \\
\text { delivery - no } \\
\text { significant } \\
\text { difference }\end{array}$ & $\begin{array}{l}\text { Headache was } \\
\text { significantly } \\
\text { reported } \\
\text { in GTN arm }\end{array}$ & $\begin{array}{l}\text { No statistical } \\
\text { difference }\end{array}$ \\
\hline $\begin{array}{l}\text { Kavita Agarwal } \\
\text { et al; } 2014^{16}\end{array}$ & Not measured & $\begin{array}{l}\text { ISMN arm - } \\
\text { significantly } \\
\text { improved } \\
(p=0.002) \\
\text { PGE2 arm } \\
\text { - significantly } \\
\text { improved } \\
(p=0.002)\end{array}$ & $\begin{array}{l}\text { PGE2 arm - } \\
\text { significant } \\
\text { shorter intervel } \\
(\mathrm{p}<0.001)\end{array}$ & Not compared & $\begin{array}{l}\text { Headache and } \\
\text { palpitation was } \\
\text { significantly } \\
\text { increased in } \\
\text { ISMN arm } \\
(\mathrm{p}<0.001) \\
\text { Tachysystole } \\
\text { significantly } \\
\text { high in } \\
\text { PGE2 arm } \\
(\mathrm{p}<0.001)\end{array}$ & $\begin{array}{l}\text { Non reassuring } \\
\text { CTG was } \\
\text { significantly } \\
\text { high in ISMN } \\
(p=0.001)\end{array}$ \\
\hline
\end{tabular}

\section{Discussion}

This double blinded randomized control clinical trial was carried out to compare the effectiveness of intravaginal GTN plus ASM versus ASM alone. The main objectives were to compare spontaneous onset of labor, modified Bishop's score differences, mean time from induction to delivery, primary mode of delivery and adverse feto-maternal complications between two arms. Stratified sample randomization method was used in two groups (intervention and control) and two arms (primi, multi). Exclusion criteria were formulated to reduce the compounding effect. The both interpreter and patient were kept blind to reduce the bias.

The study showed that using of intravaginal glyceryl trinitrate increases the spontaneous onsets of labour in women within 24 hours in both primi and multiparity women compared to ASM alone. Combination of GTN and sweeping membranes may give synergistic effect rather than sweeping alone.

In addition to ripening of the cervix, GTN will improve MBS of both primi and multigravida. Moreover, multigravida mothers showed statistically significant improvement in modified Bisoph's score compared to primi. This is because, their cervix responds more to the sweeping of membranes and synergistic effect of GTN, making early delivery. Hence, it is suggested that intravaginal nitrate can be used effectively in labour setting to ripen the cervix.

Also, Intravaginal GTN reduces the induction to delivery time in both primi and multipara women. In 
multigravid group, reduction of induction to delivery time was statistically significant. This may occur due to GTN effectively ripen the cervix prior to the induction of labour. Therefore, usage of GTN can reduce the labour duration, prevents prolonged labour, reduces labour pain and reduces the usage of additional oxytocin $^{6,7,18}$.

Other potential benefit of GTN are lower rate of hyperstimulation and tachysystole compared to wellknown PGE2. The reason is GTN ripens the cervix without uterine contraction, although actual pathophysiology is not well understood. It may have antagonist effect on the uterine myometrium.

GTN also has lesser maternal side effects such as, increased pain, maternal hypotension and postural tachycardia. Other ripening methods like prostaglandin have more systemic side effects including hypotension, allergy and fever. Compared to GTN, other groups of nitric oxide donors like ISMN, ISDN have reported incidence of hypotension and tachycardia. Thus, GTN is safer when used in intravaginal route.

Other ripening methods are associated with adverse outcomes like meconium stain liquor, abnormal fetal CTG changes and intra-partum fetal death ${ }^{10,12,13}$. Intravaginal GTN does not cause any contraction of the uterus thus not increase the fetal distress, meconium stain liquor or abnormal CTG changes. In this study no fetal deaths were recorded.

Results of the previous similar research were analyzed and summarized on Table 7. According to Filmena $\mathrm{P}$ et al; $2005^{7}$, there was no significant difference in spontaneous onset of labour (SOL) between GTN versus dinoprostone. However, Bishop's score improvement and reduction of induction to delivery time was significantly high in GTN arm.

Kavita Agarwal et al; $2014^{18}$ and Filmena P et al; 20057 showed that induction to delivery time has significantly reduced in intervention arm, but the adverse outcomes in GTN like headache and palpitations were commonly encountered. Kavita Agarwal et al; 2014 ${ }^{18}$, has reported headache in significant population (46\%) and palpitation in $12 \%$.

Yuthika Sharma ${ }^{6}$ has mentioned that there was significant improvement in Bishop's score in using GTN but no significant difference in induction to delivery time and mode of delivery in either arm Table 7.
Strength of this study are study design of double blinded randomized clinical trial, minimum bias and variables were equally matched between two groups of intervention and control. One of the limitations is the dosage of glyceryl trinitrate. The usual dose of GTN, which is used by us, was $500 \mathrm{mcg}$. It is the standard dose mentioned in literature. But no specific intravaginal standard dose or frequency were mentioned in literature. Furthermore, trials are needed to establish an optimal dose and frequency. In our study, specific time duration like duration of the latent phase and active phase of second stage and third stage were not assessed separately. For more accurate data, assessment of specific labour stages may be important and how do they change with GTN must be established in further studies. The long-term effect on the human fetuses was not properly established. Thus, phase III/ IV clinical trials need to be carried out to establish the long-term safety.

Conclusions are, intravaginal glyceryl trinitrate combined with artificial sweeping of membrane improves the spontaneous onset of labour at term, improves the modified Bishop's score and reduces induction to delivery time. When cervical ripening is done in combination of glyceryl trinitrate with artificial sweeping of membrane fewer incidents of adverse maternal outcome occur except headache. Major fetal outcomes do not observe with intravaginal glyceryl trinitrate. My recommendations are intravaginal glyceryl trinitrate combined with sweeping of membrane can be used in the clinical setting due to synergistic effect and lesser side effect profile, future trials should be carried out to establish the dose, frequency and minor vaginal side effects of intravaginal glyceryl trinitrate. Safety of the intravaginal glyceryl trinitrate should be established in a large clinical trial. Furthermore, GTN can be used in outpatient setting as a cervical ripening agent. Further research is needed to address these issues.

\section{References}

1. Gerald P. Marquette, Jennifer A. Hutcheon, Lily Lee, Predicting the Spontaneous Onset of Labour in Post-Date Pregnancies: A Population-Based Retrospective Cohort Study, Journal of Obstetrics and Gynaecology Canada, 2014; 36(5): 391. https://doi.org/10.1016/s1701-2163(15)30584-3

2. Denison FC, Price J, Graham C, Wild S, Liston WA. Maternal obesity, length of gestation, risk of postdates pregnancy and spontaneous onset of 
labour at term. British Journal of Obstetrics and Gynaecology. 2008; 115(6): 720-725. https:// doi.org/10.1111/j.1471-0528.2008.01694.x

3. Martina Delaney, Anne Roggensack, Dean C. Leduc, Charlotte Ballermann, Anne Biringer, Martina Delaney, Loraine Dontigny, Thomas P. Gleason, Lily Shek-Yn Lee, Marie-Jocelyne Martel, Valérin Morin, Joshua Nathan Polsky, Carol Rowntree, Debra-Jo Shepherd, Kathi Wilson, Guidelines for the Management of Pregnancy at $41+0$ to $42+0$ Weeks, Journal of Obstetrics and Gynaecology Canada, 2008; 30: (9) 800https://doi.org/10.1016/ S1701-2163(16)32945-0

4. Aaron B. Caughey, Victoria V. Snegovskikh, Errol R. Norwitz, Post term Pregnancy: How Can We Improve Outcomes, Obstetrical and Gynecological Survey, 2008; 63(11): 715.

https://doi: 10.1097/OGX.0b013e318186a9c7

5. National Institute for clinical excellence (NICE). Inherited Clinical Guideline - Induction of Labour, july2008.[Accessed 2016 Jul 01] Available from http://guidance.nice.org.uk/CG70/NICEGuidance/ pdf/English

6. Sharma Y, Kummar S, Mitta S, Misra R, Dadwal V, Evaluation of Glycerol trinitrate, Misoprostol, PGE2 for pre induction and cervical ripening at term. Journal of Obstetric and Gyanecology 2005; 31(3): 210-5 https://doi.org/10.1111/j.14470756.2005.00271.x

7. Nunes Felomena P, Campos AP, Pedroso SR, Leite CF, Avillez TP, Rodrigues RD, Meirinho M.Intravaginalglyceryl trinitrate and dinoprostone for cervical ripening and induction of labor, American Journal Obstetetrics and Gynaecology. 2006; 194(4):1022-6. https://doi.org/10.1016/ j.ajog.2005.10.814

8. Chanrachakul B, Herabutya Y, Punyavachira P. Randomized comparison of glyceryl trinitrate and prostaglandin E2 for cervical ripening at term. International Journal of Gynaecology and Obstetetrics. 2012; 118(3): 205-9. https://doi.org/ 10.1016/s0029-7844(00)00990-х

9. Rameez MFM, Goonewardena IMR. Nitric oxide donor isosorbidemononitrate for pre-induction cervical ripening at 41 weeks' gestation: A randomized controlled trial. Journal of Obstetrics and Gynaecology Research 2007; 33(4): 452-456. https://doi.org/10.1111/j.1447-0756.2007.00573.x

10. Boulvain M1, Stan C, Irion O. Membrane sweeping for induction of labour. Cochrane database systemic review, 2005; 25(1): CD000451 https:// doi.org/10.1002/14651858.cd000451.pub2

11. Emmanuel OnyebuchiUgwu, Samuel Nnamdi Obi, Eric Sunday Iferikigwe, Cyril Chukwudi Dim, Frank OkechukwuEzugwu, Membrane stripping to prevent post-term pregnancy in Enugu, Nigeria: a randomized controlled trial, Archives of Gynaecology and Obstetrics, 2014; 289(1): 29. https://doi.org/10.1007/s00404-013-2918-5

12. Ellen L Mozurkewich, Julie L Chilimigras, Deborah R Berman, Uma C Perni, Vivian C Romero, Valerie $\mathrm{J}$ King, Kristie L Keeton, Methods of induction of labour: a systematic review, BMC Pregnancy and Childbirth 2011; 11 (1): 84. https://doi.org/10.1186/ 1471-2393-11-84

13. Heinemann J, Gillen G, Sanchez-Ramos L, Kaunitz AM. Do mechanical methods of cervical ripening increase infectious morbidity? A systematic review. American Journal of Obstetrics and Gynecology 2008; 199(2):177-88. https://doi.org/10.1016/ j.ajog.2008.05.005

14. Bishop EH. Pelvic scoring for elective induction. Obstetrics and Gynecology 1964; 24(2): 266-268.

15. Goonewardene M, Rameez MFM, Kaluarachchi A, Perera $\mathrm{H}$. WHO recommendations for induction of labour: RHL commentary. The WHO Reproductive Health Library. Geneva: World Health Organization;1996.

16. glyceroltrinitrate.drugs.com, accessed on 01 July 2016.

17. Kavita Agarwal, Aruna Batra, Achla Batra, Anjali Dabral, Abha Aggarwal, Evaluation of isosorbidemononitrate for cervical ripening prior to induction of labor for postdated pregnancy in an outpatient setting, International Journal of Gynecology \& Obstetrics, 2012; 118(3): 205. https://doi.org/10.1016/j.ijgo.2012.04.017

18. Kavita Agarwal, Achla Batra, Aruna Batra, Abha Aggarwal. Randomized Comparison of Isosorbide Mononitrate and PGE2 Gel for Cervical Ripening at Term including High Risk Pregnancy, International Journal of Reproductive Medicine, 2014; 2014 (1). https://doi.org/10.1155/2014/147274

19. Justus Hofmeyr G, MetinGülmezoglu A, Cynthia Pileggi, Justus Hofmeyr G. Vaginal Misoprostol for cervical ripening and induction of labour. Cochrane Database of Systematic Reviews, 2010. https://doi.org/10.1002/14651858.cd000941.pub2

20. Kasiulevicius V, Sapoka R, Filipaviciute. Sample size calculation in epidemiological studies. Gerontology 2006; 7(4): 225-231. 